\title{
MAXIMAL PREVENTIVE REACTIVE POWER DISPATCH USING MULTI-OBJECTIVE FUZZY BASED PROCEDURE
}

\author{
A. A. El-Ela, R. A. El Sehiemy and Abdul A. M. Shaheen \\ Electrical Engineering Department, Faculty of Engineering, \\ Minoufiya University, Shebin El-Kom, Egypt
}

\begin{abstract}
This paper presents a proposed procedure for maximal preventive reactive power control actions using the multi-objective fuzzy linear programming (MFLP) technique to overcome any emergency condition may be occurred. The proposed procedure is very significant to eliminate violation constraints and give an optimal reactive power reserve for multi-operating conditions. The proposed multi-objective functions are: minimizing the real transmission losses, maximizing the reactive power reserve at certain generator, maximizing the reactive power reserve at all generation systems and/or switchable VAR devices. The proposed MFLP is applied to 5-bus test system and the West Delta region system as a part of the Egyptian Unified network. The numerical results show that the proposed MFLP technique achieves a minimum real power loss with maximal reactive reserve for power systems for different operating conditions.

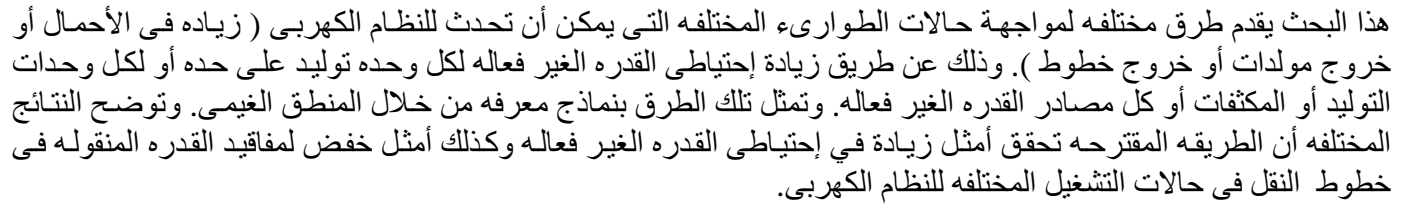

Keywords: Real transmission losses, reactive power reserve, preventive reactive power control actions, Triangular fuzzy modeling, multi-objective fuzzy linear programming.

\section{INTRODUCTION}

One of the major operating tasks of a power system is to maintain the load bus voltages within their limits for high quality consumer services. The electric power loads are not constant and varies from time to time. Any change in the power demand causes lower or higher voltages [1]. The loss minimization is one of the important objectives in operating the transmission networks [2]. In a typical power system, network losses account for 5 to $10 \%$ of the total generation in the power system, which would cost millions of dollars every year [3]. This objective can be achieved by achieving proper adjustments of control variables like generator bus voltage magnitude $\left(\mathrm{vg}_{\mathrm{i}}\right)$, transformer tap settings $\left(\mathrm{t}_{\mathrm{ij}}\right)$, and reactive power injected from switchable capacitor banks $\left(\mathrm{QS}_{\mathrm{j}}\right)$ while satisfying the units and system constraints. The optimal reactive power dispatch problem is solved effectively by conventional optimization techniques such as Newton method [4], linear programming (LP) [5], dynamic programming [6], nonlinear programming
[7], quadratic programming [8, 9] and interior point methods [10] and also by computational intelligencebased techniques such as genetic algorithm (GA) [11], particle swarm optimization (PSO) $[12,13]$ and differential evolution (DE), [14, 15].

Appropriate provision for reactive power is essential for power systems in order to ensure secure and reliable operation of power systems. Reactive power is tightly related to bus voltages throughout a power network, and hence reactive power services have a significant effect on system security. Insufficient reactive power supply can result in voltage collapse, which has been one of the reasons for some recent major blackouts [16].

Ref. [17] described an OPF based approach for assessing the minimal reactive power support for generators in deregulated power systems. Ref. [18] presented a method to optimize reactive power flow (ORPF) with respects to multiple objectives while maintaining voltage security. The management of reactive power reserves in order to improve static voltage stability by using a modified particle swarm optimization algorithm was presented in [19]. Due to 
the ability of fuzzy logic to represent the sorts of qualitative statements employed by human, fuzzy logic has found favor among many engineers and its effectiveness in solving multi objective problems. Fuzzy systems have been increasingly used to develop more efficient schemes for the power system operation, planning, control, and management. The status of fuzzy system applications to power systems and future considerations of fuzzy system applications were presented in [20-22].

There are various types of membership functions which are commonly used in fuzzy set theory. The choice of shape depends on the individual application. Different fuzzy models have been presented in [23] to solve the fuzzy-based optimal power dispatch problem. Ref. [24] solved the optimal active power dispatch problem considering multiobjective fuzzy linear programming technique considering preventive action constraints. This paper presents the solution of the fuzzy security constrained ORPF problem with maximizing the preventive control action. The overall objective is to minimize the real power losses, maximize the reactive power reserve, while satisfying all the variables within their limits.

\section{SOLUTION METHODOLOGY}

The optimal reactive power dispatch is solved using MFLP technique to determine the optimal settings of control variables with efficient fine tuning of power system variables where the real power losses are minimized and the maximal of preventive control action is achieved by increasing the reactive power reserve of generators and switchable VAr sources.

\subsection{Fuzzy Based ORPD Problem}

The fuzzy optimal reactive power dispatch problem is formulated as a fuzzified constrained optimization problem to minimize the real power losses. In this paper, the simple sensitivity parameters are used to represent the objectives and dependent variables in terms of the control variables [25].

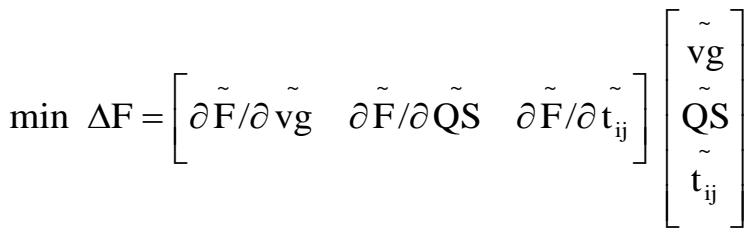
Subjected to

$$
\begin{aligned}
& \Delta \mathrm{vg}_{\mathrm{i}}{ }^{\min } \leq \Delta \tilde{\mathrm{vg}}_{\mathrm{i}} \leq \Delta \mathrm{vg}_{\mathrm{i}}{ }^{\max } \\
& \mathrm{i} \in \mathrm{Ng} \text { - slack bus } \\
& \Delta \mathrm{QS}_{\mathrm{j}}{ }^{\text {min }} \leq \Delta \tilde{\mathrm{QS}}_{\mathrm{j}} \leq \Delta \mathrm{QS}_{\mathrm{j}}{ }^{\max } \quad \mathrm{j} \in \mathrm{Ns} \\
& \Delta \mathrm{t}_{\mathrm{ij}}{ }^{\min } \leq \Delta \tilde{\mathrm{t}}_{\mathrm{ij}} \leq \Delta \mathrm{t}_{\mathrm{ij}}{ }^{\max } \quad \mathrm{i}, \mathrm{j} \in \mathrm{Nt} \\
& \Delta \mathrm{vl}_{\mathrm{i}}{ }^{\text {min }} \leq \Delta \tilde{\mathrm{vl}}_{\mathrm{i}} \leq \Delta \mathrm{vl}_{\mathrm{i}}{ }^{\max } \quad \mathrm{i} \in \mathrm{Nb}-\mathrm{Ng} \\
& \Delta \mathrm{QG}_{\mathrm{j}}{ }^{\text {min }} \leq \Delta \tilde{Q G}_{\mathrm{j}} \leq \Delta \mathrm{QG}_{\mathrm{j}}{ }^{\max } \quad \mathrm{j} \in \mathrm{Ng} \text {-slack bus }
\end{aligned}
$$

$\Delta \mathrm{Qf}_{\mathrm{k}}{ }^{\min } \leq \Delta \tilde{\mathrm{Qf}}_{\mathrm{k}} \leq \Delta \mathrm{Qf}_{\mathrm{k}}{ }^{\max } \quad \mathrm{k} \in \mathrm{Nl}$

Where $(\tilde{\mathrm{F}})$ is the fuzzy real losses in the transmission network; ( $\tilde{v} g, \tilde{v l}$ ) is the fuzzy bus voltage of generator and load buses respectively; ( QS ) is the fuzzy reactive output from the switchable bus; $\left(\tilde{\mathrm{t}}_{\mathrm{j}}\right)$ is the fuzzy tap point of the transformer tap changer; ( $\tilde{Q} G$ ) is the fuzzy reactive output from generators and ( $\tilde{Q} f$ ) is the fuzzy reactive flow through lines. Ng is the number of generators; Ns is the number of switchable buses; Nt is the number of transformer tap changer; $\mathrm{Nb}$ is the number of buses; $\mathrm{Nl}$ is the number of transmission lines. The symbols (min, max and $\Delta$ ) refer to minimum, maximum and gradient of any variable, respectively. The dependent variables (y) are represented in terms of control variables $(\mathrm{x})$.

$$
\mathrm{y}=\mathrm{C}_{\mathrm{yx}} \cdot \mathrm{x}
$$

Where, $\mathrm{C}_{\mathrm{yx}}$ is the sensitivity parameters of the dependent variables in terms of the control variables [25].

\subsection{Reactive Power Reserve}

The maximization of reactive reserve problem is formulated as an optimization problem whose objectives are (i) maximizing the reactive power reserves as a preventive control action for any emergency may be occurred (ii) minimizing the real power losses with respect to current operating point. Reactive power reserve of the generators is the ability of the generators to support bus voltages under increased load or disturbance condition.

The reactive power reserve of any generator can be represented as:

$$
\mathrm{QG}_{\mathrm{i}, \text { es }}=\mathrm{QG}_{\mathrm{i}, \max }-\mathrm{QG}_{\mathrm{i}} \quad, \mathrm{i}=1,2, \ldots \ldots \ldots \ldots \ldots \ldots . . \mathrm{Ng}
$$

Where, $\mathrm{QG}_{\mathrm{i}, \text { res }}$ is the reactive power reserve of generator $\mathrm{i} ; \mathrm{QG}_{\mathrm{i}, \max }$ is the maximum limit of reactive power output of generator $i$ which is the maximum limit of reactive power that the machine can supply; $\mathrm{QG}_{\mathrm{i}}$ is the reactive power output of generator $\mathrm{i}$ at a certain operating condition.

The reactive power reserve of switchable VAR devices can be represented as:

$$
\mathrm{QS}_{\mathrm{j}, \mathrm{res}}=\mathrm{QS}_{\mathrm{j}, \max }-\mathrm{QS}_{\mathrm{j}} \quad, \mathrm{i}=1,2, \ldots \ldots \ldots \ldots \ldots \ldots . . . \mathrm{Ns}
$$

(1)Where, $\mathrm{QS}_{\mathrm{j}, \text { res }}$ is the reactive power reserve of a switchable $\mathrm{VAr}$ source at bus $\mathrm{j}$; $\mathrm{QS}_{\mathrm{j}, \max }$ is the maximum limit of reactive power output of a switchable VAr source at bus $\mathrm{j}_{\text {; }} \mathrm{QS}_{\mathrm{j}}$ is the reactive power output of a switchable VAr source at bus $j$ at a

(2) certain operating condition.

\subsection{Fuzzy Modeling}

There are various types of membership functions which are commonly used in fuzzy set theory to solve the optimal active power dispatch in power systems [23]. One of the best membership functions 
to represent the control and dependent variables in power systems was the triangular shape $[24,26]$.

\subsubsection{Fuzzy modeling of constraints}

The triangle fuzzy modeling for the control variables (x) is shown in Fig. 1. These control variables are the voltage at generators buses $\left(\mathrm{vg}_{\mathrm{i}}\right)$, reactive power output at switchable buses $\left(\mathrm{QS}_{\mathrm{j}}\right)$ and transformer tap changer $\left(t_{i j}\right)$. It is seen that a membership function equal to 1 is assigned to $x_{i}^{\text {med }}$. Each control variable is represented by two constraints for the upper and lower limits. The membership function for the lower limit of any control variable is described as:

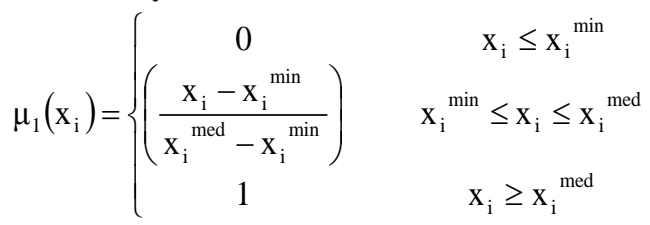

And the upper limit membership function of any control variable is described as:

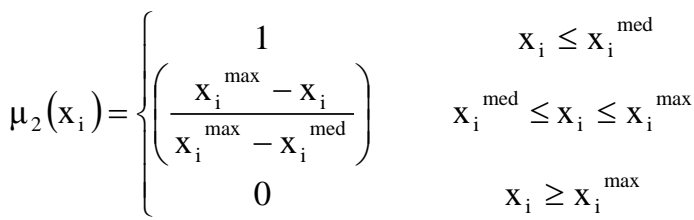

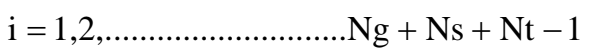

Where, $x_{i}{ }^{\min }$ and $x_{i}$ max are the minimum and maximum limits of a control variable $\left(\mathrm{x}_{\mathrm{i}}\right)$, respectively. While, $x_{i}{ }^{\text {med }}$ is a point between the minimum and maximum limits of the control variables, with best tuning of the control variables especially the generators voltage to enforce it towards desired values to enhance voltage security and it is less than the maximum limit of each one. Similarly, a triangle fuzzy modeling for the dependent variables $\left(y_{j}\right)$ is shown in Fig. 2. It is seen that a membership function equal to 1 is assigned to $\mathrm{y}_{\mathrm{j}}{ }^{\mathrm{med}}$. Each dependent variable is represented by two linear constraints for the upper and lower limits. The membership function for lower limit of any dependent variable is described as:

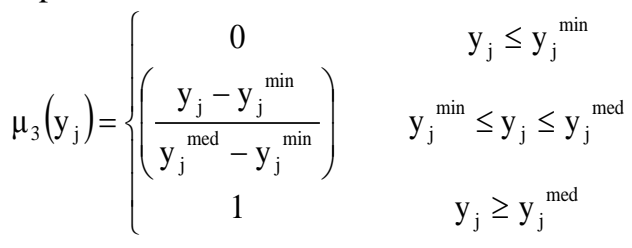

And the upper limit membership function of any dependent variable is described as:

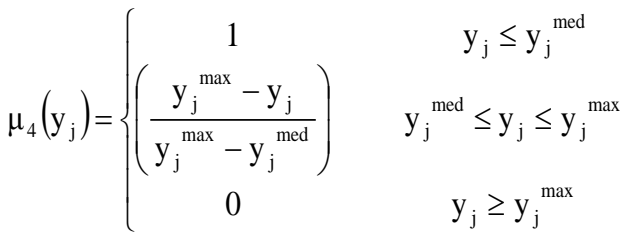

$$
\begin{aligned}
& \mathrm{j}=1,2, \ldots \ldots \ldots \ldots \ldots \ldots \ldots \ldots \ldots . . . \mathrm{Nb}+\mathrm{Nl}
\end{aligned}
$$

Where, $y_{j}{ }^{\min }$ and $y_{j}{ }^{\max }$ are the minimum and maximum limits of each dependent variable $\left(\mathrm{y}_{\mathrm{j}}\right)$, respectively. While $y_{j}{ }^{\text {med }}$ is a point between the minimum and maximum limits of each dependent variable and it is less than the maximum limit of each one.

\subsubsection{The objective fuzzy modeling}

Different objective functions are introduced in the proposed procedure. These objectives are minimizing the total real power losses and maximizing the reactive power reserve for generators and switchable VAR sources. The fuzzy modeling of the real power losses (F) is shown in Fig. 3. Eq. (15) can represent the fuzzy membership function of the real losses which is less than or equal the permissible losses as:

$$
\mu_{5}(F)=\left\{\begin{array}{cc}
1 & F \leq F^{\min } \\
\left(\frac{F^{\max }-F}{F^{\max }-F^{\text {med }}}\right) & F^{\min } \leq F \leq F^{\max } \\
0 & F \geq F^{\max }
\end{array}\right.
$$

Where, $F^{\min }$ and $F^{\max }$ are the minimum and maximum real power losses which are related to the minimum and maximum reactive power dispatch of the power system, respectively at a certain reactive power demand. The fuzzy membership function for maximizing the reactive power reserve can be represented in Eq. (16) as shown in Fig. 4.

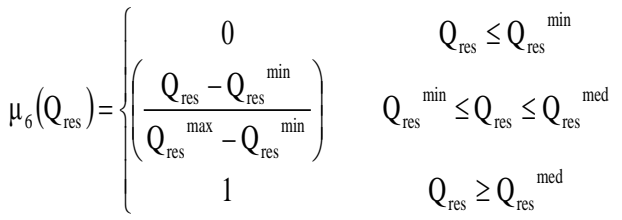

Where, $\mathrm{Q}_{\text {res }}{ }^{\min }$ and $\mathrm{Q}_{\text {res }}{ }^{\max }$ are the minimum and maximum reactive power reserve for the VAR sources in the power system, respectively.

\section{PROPOSED PROCEDURE FOR MAXIMAL REACTIVE RESERVE}

The proposed objectives to maximize the reactive power reserve either for all sources of static and dynamic reactive power or individual are incorporated to the fuzzy linear programming technique. Then, the optimal reactive power dispatch is applied at an operating condition as shown in section 2-1. These objectives are considered as various preventive control actions that may be taken into account to remove any violation limit, which may occur at the emergency condition.

\subsection{Maximization of Reactive Power Reserve for Each Generation Unit}

The maximal effect of the preventive control action, to maximize the reactive power reserve for each generation unit, can be expressed as: $\max \mathrm{QG}_{\mathrm{i}, \mathrm{re}}$

$$
\mathrm{QG}_{\text {io }}-\tilde{\mathrm{QG}}_{\mathrm{i}} \leq \mathrm{QG}_{\mathrm{i}, \mathrm{res}}
$$

Where, $\mathrm{QG}_{\mathrm{io}}$ is the initial reactive generation of unit $\mathrm{i} ; \mathrm{QG}_{\mathrm{i}}$ is the fuzzy reactive generation of new 
operating condition for generator $\mathrm{i}$; $\mathrm{QG}_{\mathrm{i}, \mathrm{res}}$ is the maximal reactive reserve for generator $i$ at a certain operating condition which is defined in Eq. (9).

\subsection{Maximization of Reactive Power Reserve for All Generation Units}

Eq. (17) is restated, as a multi-objective problem to obtain the maximal reactive power reserve for all generation units except the slack bus generator simultaneously, as:

$\max \mathrm{QG}_{\mathrm{i}, \text { res }}$

$$
\begin{aligned}
\mathrm{QG}_{\mathrm{i} 0}-\tilde{\mathrm{QG}}_{\mathrm{i}} \leq \mathrm{QG}_{\mathrm{i}, \text { res }}, \mathrm{i}= & 1,2, \ldots \ldots \ldots \ldots \ldots . . . \mathrm{Ng} \\
\mathrm{i} & \neq \text { slack bus }
\end{aligned}
$$

Where, $\mathrm{QG}_{\mathrm{io}}$ is the initial reactive power generation for unit $\mathrm{i} ; \mathrm{QG}_{\mathrm{i}}$ is the fuzzy reactive generation of new operating condition for generator $\mathrm{i}$; $\mathrm{QG}_{\mathrm{i} \text {,res }}$ is the maximal reactive reserve for generator $\mathrm{i}$ at certain operating condition which is defined in Eq. (9).

\subsection{Maximization of Reactive Power Reserve at Switchable Buses}

The maximal reactive reserve for all switchable VAR devices can be expressed as:

$\max \mathrm{QS}_{\mathrm{j}, \mathrm{res}}$

$$
\mathrm{QS}_{\mathrm{jo}}-\tilde{\mathrm{QS}}_{\mathrm{j}} \leq \mathrm{QS}_{\mathrm{j}, \mathrm{res}} \quad, \mathrm{j}=1,2 \ldots \ldots \ldots \ldots . . . \mathrm{Ns}
$$

Where, $\mathrm{QS}_{\mathrm{jo}}$ is the initial reactive output for all switchable buses; $\mathrm{QS}_{\mathrm{j}}$ is the fuzzy reactive output of new operating condition for all switchable buses ; $\mathrm{QS}_{\mathrm{j}, \text { res }}$ is the maximal reactive reserve for all switchable buses at certain operating condition which is defined in Eq. (10).

\subsection{Multi-objective Fuzzy Linear Programming Technique}

Since, the maximization of reactive power reserve problem has proposed multiple objective function, the MFLP technique is performed by maximizing the minimum of all satisfaction parameters as maximize $\lambda$, where:

$\lambda=\min \left\{\mu_{\mathrm{z} 1}, \mu_{\mathrm{z} 2} \ldots \ldots \ldots \ldots \ldots, \mu_{\mathrm{zi}}\right\}$

Where, $\mu_{\mathrm{zi}}$ is the membership functions of the constraints for control and dependent variables as well as the objectives constraints of real power losses and reactive power reserves, within range of [0-1] for all constraints. Thus, the fuzzy reactive power dispatch presented in Eqs. (1)-(7) with maximizing the reactive power reserve can be expressed as follows:

$\max \lambda$

subjected to

$$
\begin{array}{lc}
\lambda \leq \mu_{\mathrm{z} 1}\left(\mathrm{x}_{\mathrm{i}}\right) & \mathrm{i}=1,2, \ldots \ldots . . \mathrm{Ng}+\mathrm{Ns}+\mathrm{Nt}-1 \\
\lambda \leq \mu_{\mathrm{z} 2}\left(\mathrm{y}_{\mathrm{j}}\right) & \mathrm{j}=1,2, \ldots \ldots \ldots \mathrm{Nk}+\mathrm{Nb}-1 \\
\lambda \leq \mu_{\mathrm{z} 3}(\mathrm{~F}) & \\
\lambda \leq \mu_{\mathrm{z} 4}\left(\mathrm{Q}_{\mathrm{res}, \mathrm{m}}\right) & \mathrm{m}=1,2, \ldots \ldots . . \mathrm{Nm}-1
\end{array}
$$

$0 \leq \lambda \leq 1$

Where, $\mu_{z 1}\left(x_{i}\right)$ is the fuzzy membership function for control variables $x_{i} ; \mu_{z 2}\left(y_{j}\right)$ is the fuzzy membership function for dependent variables $y_{j} ; \mu_{z 3}(F)$ is the fuzzy membership function for the real power losses; $\mu_{\mathrm{z} 4}\left(\mathrm{Q}_{\mathrm{res}, \mathrm{m}}\right)$ is the fuzzy membership function for the reactive power reserve as a second objective; $\mathrm{Nm}$ is the number of objective functions of reactive power reserve. Eqs (21)-(25) can be rewritten as follows:

$$
\begin{aligned}
& -\mathrm{x}_{\mathrm{i}}+\left(\mathrm{x}_{\mathrm{i}}^{\text {med }}-\mathrm{x}_{\mathrm{i}}^{\mathrm{min}}\right) \lambda \leq-\mathrm{x}_{\mathrm{i}}^{\text {min }} \\
& \mathrm{i}=1,2, \ldots \ldots \ldots \ldots . . \mathrm{Ng}+\mathrm{Ns}+\mathrm{Nt}-1 \\
& -\mathrm{y}_{\mathrm{j}}+\left(\mathrm{y}_{\mathrm{j}}^{\mathrm{med}}-\mathrm{y}_{\mathrm{j}}^{\mathrm{min}}\right) \lambda \leq-\mathrm{y}_{\mathrm{j}}^{\text {min }} \\
& \mathrm{j}=1,2, \ldots \ldots \ldots \ldots . . . \mathrm{Nk}+\mathrm{Nb}-1 \\
& \mathrm{x}_{\mathrm{i}}+\left(\mathrm{x}_{\mathrm{i}}^{\mathrm{max}}-\mathrm{x}_{\mathrm{i}}^{\text {med }}\right) \lambda \leq \mathrm{x}_{\mathrm{i}}^{\max } \\
& \mathrm{i}=1,2, \ldots \ldots \ldots \ldots . . . \mathrm{Ng}+\mathrm{Ns}+\mathrm{Nt}-1 \\
& y_{j}+\left(y_{j}^{\text {max }}-y_{j}^{\text {med }}\right) \lambda \leq y_{j}^{\text {max }} \\
& \mathrm{j}=1,2, \ldots \ldots \ldots \ldots . . . \mathrm{Nk}+\mathrm{Nb}-1 \\
& \mathrm{~F}+\left(\mathrm{F}^{\max }-\mathrm{F}^{\mathrm{min}}\right) \lambda \leq \mathrm{F}^{\max } \\
& -\mathrm{Q}_{\text {res }, \mathrm{m}}+\left(\mathrm{Q}_{\mathrm{res}, \mathrm{m}}^{\max }-\mathrm{Q}_{\mathrm{res}, \mathrm{m}}^{\min }\right) \lambda \leq-\mathrm{Q}_{\mathrm{res}, \mathrm{m}}^{\min } \\
& \mathrm{m}=1,2, \ldots \ldots \ldots \ldots . . \mathrm{Nm} \\
& 0 \leq \lambda \leq 1
\end{aligned}
$$

Eqs. (26)-(31) represent the fuzzy constraints of generators voltage, reactive power output at switchable buses, transformers tap setting, loads voltage, reactive power output from the generators, reactive power flow in the transmission lines, real power losses as objective function and the reactive power reserve as a second objective function. The MFLP technique is computed to maximize $\lambda$, using these fuzzy constraints.

\section{APPLICATIONS}

\subsection{Test Systems}

The 5-bus test system and the West Delta region systems [27] are used for an extensive study to maximize the optimal reactive power reserve. The proposed MFLP technique is applied to minimize the real transmission losses and maximize the reactive power reserves using the 5-bus test system (3generation units, 7-lines). The line diagram of the 5bus test system is shown in Fig. 5. Table 1 and 2 show the transmission line data and bus-data for 5bus test system, respectively. The second test system is West Delta region system as a part of the Unified Egyptian Network which consists of 52-bus and 8 generation buses. These buses are connected by 108 lines [27]. Figure 6 shows the one line diagram of the real power system for West Delta region. Shunt compensation limits at buses 18, 20 and 42 have been assumed between 0 p.u and 1 p.u (the base voltage is $66 \mathrm{kV}$, while the base MVA is 100). On Load Tap Changer (OLTC) limits between buses 425 and 11-28 have been assumed between 0.9 and 1.1 p.u. 


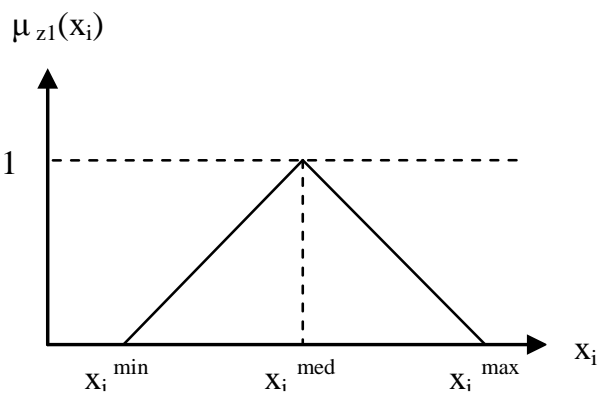

Fig. 1 Triangular membership model For control variables $\left(\mathrm{x}_{\mathrm{i}}\right)$ $\mu_{\mathrm{z} 3}(\mathrm{~F})$

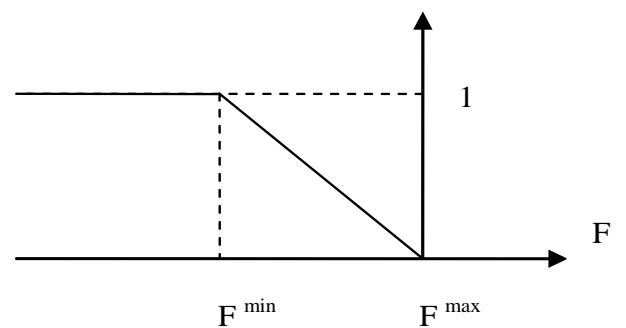

Fig. 3 Fuzzy membership model for real power losses $(\mathrm{F})$

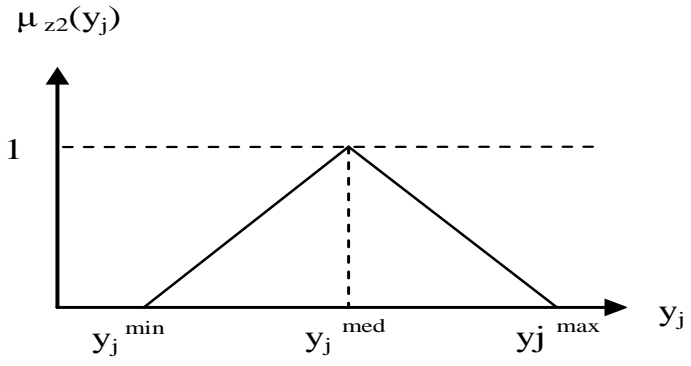

Fig 2 Triangular membership model For dependent variables $\left(\mathrm{y}_{\mathrm{j}}\right)$ $\mu_{\mathrm{z} 4}\left(\mathrm{Q}_{\mathrm{res}}\right)$

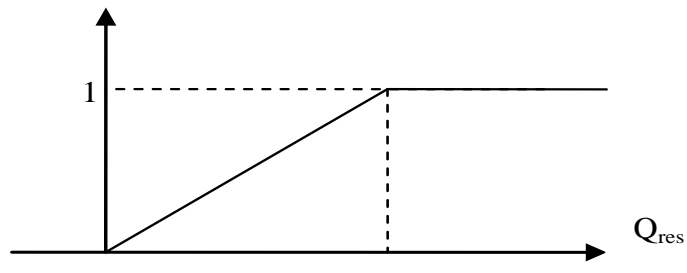

$\mathrm{Q}_{\text {res }}^{\min } \quad \mathrm{Q}_{\mathrm{res}}^{\max }$

Fig. 4 Fuzzy membership model for reactive power reserve $\left(Q_{\text {res }}\right)$

Table 1, Bus data

\begin{tabular}{|c|c|c|c|c|c|c|c|c|c|c|}
\hline $\begin{array}{c}\text { Bus } \\
\text { No }\end{array}$ & $\begin{array}{c}\text { Pg } \\
\text { (MW) }\end{array}$ & $\begin{array}{c}\text { Qg } \\
\text { (MVAr) }\end{array}$ & $\begin{array}{c}\text { Pd } \\
\text { (MW) }\end{array}$ & $\begin{array}{c}\text { Qd } \\
\text { (MVAr) }\end{array}$ & $\begin{array}{c}\text { QMAX } \\
\text { (MVAr) }\end{array}$ & $\begin{array}{c}\text { QMIN } \\
\text { (MVAr) }\end{array}$ & $\begin{array}{c}\text { V } \\
\text { (P.U.) }\end{array}$ & $\begin{array}{c}\text { Qinj } \\
\text { (P.U.) }\end{array}$ & $\begin{array}{c}\text { Vmax } \\
\text { (P.U.) }\end{array}$ & $\begin{array}{c}\text { Vmin } \\
\text { (P.U.) }\end{array}$ \\
\hline 1 & 89.57 & 89.57 & 65 & 50 & 120 & -120 & 1.05 & 0 & 1.05 & 0.95 \\
\hline 2 & 180 & 60 & 85 & 50 & 90 & -90 & 1.02 & 0 & 1.05 & 0.95 \\
\hline 3 & 0 & 0 & 75 & 45 & 100 & 0 & 0.97 & 0 & 1.05 & 0.95 \\
\hline 4 & 0 & 0 & 75 & 45 & 0 & 0 & 0.96 & 0 & 1.05 & 0.95 \\
\hline 5 & 140 & 40 & 150 & 100 & 150 & -150 & 1.02 & 0 & 1.05 & 0.95 \\
\hline
\end{tabular}

Table 2, Transmission lines data

\begin{tabular}{|c|c|c|c|c|c|c|c|}
\hline $\begin{array}{c}\text { Bus } \\
\text { No }\end{array}$ & $\begin{array}{c}\mathrm{nl} \\
\text { (from) }\end{array}$ & $\begin{array}{c}\mathrm{nr} \\
\text { (to) }\end{array}$ & $\begin{array}{c}\mathrm{R} \\
\text { (P.U.) }\end{array}$ & $\begin{array}{c}\text { X } \\
\text { (P.U.) }\end{array}$ & $\begin{array}{c}\text { BC } \\
\text { (P.U.) }\end{array}$ & $\begin{array}{c}\mathrm{a} \\
\text { (at nl side) }\end{array}$ & $\begin{array}{c}\text { Max flow } \\
\text { (MVAr) }\end{array}$ \\
\hline 1 & 1 & 2 & 0.02 & 0.06 & 0.030 & 1.0000 & 50 \\
\hline 2 & 1 & 3 & 0.08 & 0.24 & 0.025 & 1.0000 & 50 \\
\hline 3 & 2 & 3 & 0.06 & 0.18 & 0.020 & 1.0000 & 50 \\
\hline 4 & 2 & 4 & 0.06 & 0.18 & 0.020 & 1.0000 & 50 \\
\hline 5 & 2 & 5 & 0.04 & 0.12 & 0.015 & 1.0000 & 50 \\
\hline 6 & 3 & 4 & 0.01 & 0.03 & 0.010 & 1.0000 & 50 \\
\hline 7 & 4 & 5 & 0.08 & 0.24 & 0.025 & 1.0000 & 50 \\
\hline
\end{tabular}

Table 3, The maximization of reactive power reserve for 5-bus system

\begin{tabular}{|c|c|c|c|c|c|c|c|}
\hline & $\begin{array}{c}\text { Initial } \\
\text { case }\end{array}$ & case 1 & case 2-A & case 2-B & case 3 & case 4 & case 5 \\
\hline QG1 & 1.1554 & 0.3247 & 0.6386 & 0.5983 & 0.7589 & 0.3856 & 0.5602 \\
\hline QG2 & 0.3670 & 0.4236 & -0.1211 & 0.6415 & 0.0678 & 0.5721 & 0.5652 \\
\hline QG3 & 1.2838 & 1.3438 & 1.5026 & 0.8687 & 1.1197 & 1.3912 & 1.0371 \\
\hline QS 3 & 1.1554 & 0.6441 & 0.7342 & 0.6361 & 0.8000 & 0.3986 & 0.5778 \\
\hline $\mathbf{t}_{3-4}$ & 1.0000 & 1.0526 & 1.0526 & 1.0526 & 1.0526 & 1.0526 & 1.0526 \\
\hline Power losses & 0.0660 & 0.0432 & 0.0472 & 0.0467 & 0.0462 & 0.0447 & 0.0442 \\
\hline $\begin{array}{c}\text { \% Reduction in } \\
\text { power losses }\end{array}$ & & 34.5185 & 28.4837 & 29.3018 & 30.023 & 32.3498 & 32.9755 \\
\hline Total QGReserve & 0.7938 & 1.5079 & 1.5798 & 1.4916 & 1.6535 & 1.2511 & 1.4375 \\
\hline
\end{tabular}




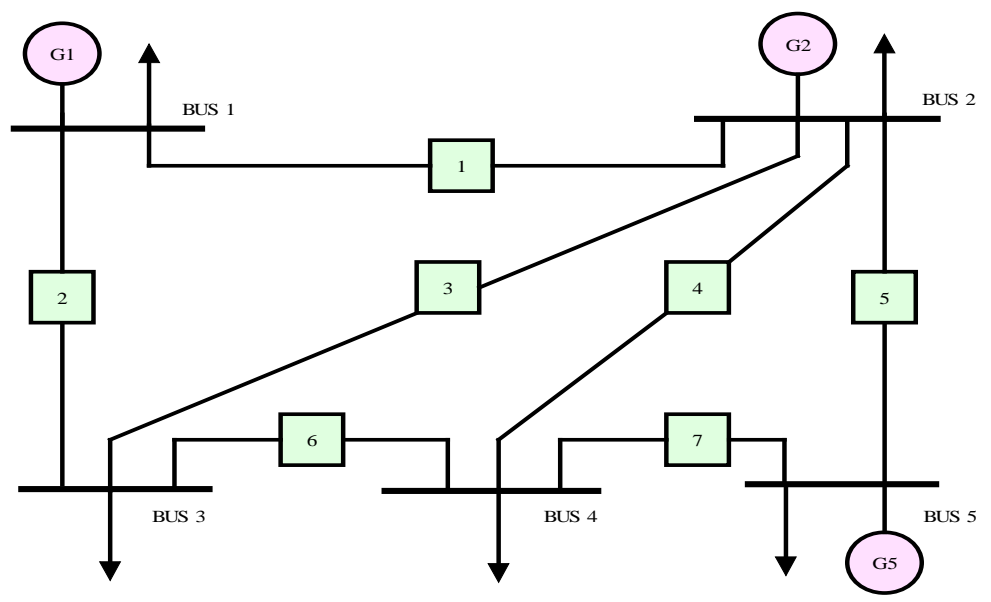

Fig. 5 Line diagram of 5-bus system

\subsection{Results and Comments}

Five cases have been studied which have the following definitions

Case 1: The fuzzy linear programming (FLP) technique is applied for the initial condition considering only the minimization of real power losses (Eq. (1)) as an objective function.

Case 2: The MFLP technique is applied for maximizing the reactive power reserve of each generation unit, individually.

Case 3: The MFLP technique is applied for maximizing the reactive power reserve of all generators except slack bus. Two objective functions are considered as constraints (Eqs. (1) and (18)).

Case 4: The MFLP technique is applied for maximizing the reactive power reserve of switchable buses. Two objectives are considered as constraints (Eqs. (1) and (19)).

Case 5: The MFLP technique is applied for maximizing preventive action of all generation units and switchable buses. Three objective functions are considered as constraints (Eqs. (1), (18) and (19)).

\subsubsection{5-bus system}

Table 3 shows the results of the FLP technique (case 1) for the initial case and the MFLP technique for the other cases 2, 3, 4 and 5. However cases (2-A)-(2-B) represent the maximal effect of the preventive actions for maximizing the reactive power reserve for generation buses 2-5, respectively. While, all the system constraints are satisfied. All the values in the table are per unit.

In case 1 , the real transmission losses are decreased from 6.6 MW to $4.32 \mathrm{MW}$ by reduction percentage equals $34.5185 \%$. In cases (2-A)-(2-B), the reactive power reserve is maximized for generators 2 and 5 individually compared with the FLP technique (case 1). However, the real power losses are slightly increased to 4.72 MW and 4.67 MW, respectively. In case 3 , the generation buses 2 and 5 has more reactive power reserve compared with case 1 , while the real power losses are slightly increased to be 4.62
MW with reduction percentage equals 30.023\%. Also, the total reactive power reserve of all generators is maximized to be 1.6535 p.u compared with all other cases. In case 4 , the maximum reactive power reserve at switchable buses is achieved to be 0.3986 p.u compared with all other cases. However, the real power losses are slightly increased compared with case 1 to be $4.47 \mathrm{MW}$ with reduction percentage equals $32.3498 \%$.

In case 5 , the reactive power reserve at generation bus 5 and switchable buses are increased. However, the real power losses are slightly increased compared with case 1 to be 4.42 MW with reduction percentage $32.9755 \%$. While, the reactive power reserve at generation bus 2 isn't increased.

\subsubsection{West Delta region system}

Similar results have been obtained for West Delta region system. Table 4 and 5 represent the results of the FLP technique (case 1) for the initial case of West Delta region system and the MFLP technique for the other cases 2, 3, 4, and 5. However cases (2A)-(2-B)-(2-C)-(2-D) represent the maximal effect of the preventive control actions by maximizing the reactive power reserve for generation buses 4, 5, 7, and 8 , respectively. While, all the system constraints are satisfied. All the values in the Tables are per unit. The Newton Raphson load flow results are shown in Table 4, and 5 as the initial case. However, the load voltages at buses 18, 20, and 21 are violated.

In case 1 , the real transmission losses are decreased from 18.08 MW to $15.58 \mathrm{MW}$ by reduction percentage equals $13.8335 \%$. In cases (2-A)-(2-B)(2-C)-(2-D), each selected generator has a maximal reactive power reserve compared with its value in case 1 . However, the real power losses are slightly increased. Case 2-C gives the same solution of case 1. In case 3 , the reactive power reserve of all generation buses is maximized (except slack bus) compared with case 1 , while the real power losses are slightly increased to $16.28 \mathrm{MW}$ with reduction percentage $9.9393 \%$. Also, the total reactive power 
A. El-Ela, R. El Sehiemy and A. Shaheen "Maximal Preventive Reactive Power Dispatch Using.."

reserves of all generation buses are maximized. In cases 4 and 5 the real power losses are increased compared with all other cases to be $0.1717 \mathrm{MW}$ and $0.1735 \mathrm{MW}$ with reduction percentage of $5.0244 \%$ and $4.0395 \%$, respectively. While, the maximization of the reactive power reserve at switchable buses is achieved at case 4 and at all generation buses (case 5). From these Tables, the system operators trades off between taking more the preventive control actions from all system generation units or from switchable buses or from both of them, simultaneously.

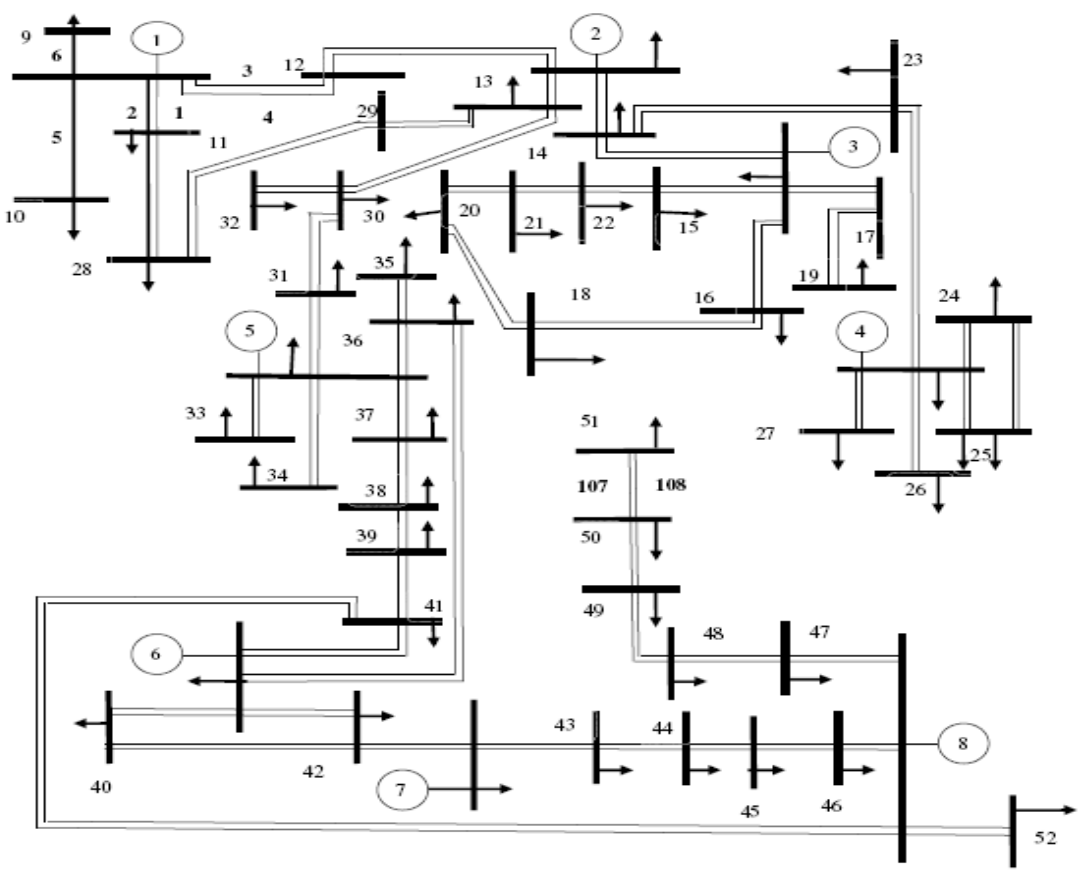

Fig. 6 Line diagram for 52-bus actual system of West-Delta region [27].

Table 4, The maximization of reactive reserve of cases 1, 2 and 3 for West Delta system

\begin{tabular}{|c|c|c|c|c|c|c|c|}
\hline & $\begin{array}{c}\text { Initial } \\
\text { case }\end{array}$ & case 1 & case 2-A & case 2-B & Case 2-C & case 2-D & case 3 \\
\hline QG1 & 0.6334 & 0.2988 & 0.2354 & 0.2354 & 0.2354 & 0.2988 & 0.2659 \\
\hline QG2 & -0.3790 & 0.1182 & 0.2779 & 0.2779 & 0.2779 & 0.1182 & 0.121 \\
\hline QG3 & 0.8700 & 0.1692 & 0.1584 & 0.1584 & 0.1584 & 0.1692 & 0.1263 \\
\hline QG4 & 0.9766 & 0.8565 & 0.8009 & 0.8009 & 0.8009 & 0.8565 & 0.8268 \\
\hline QG5 & 0.3247 & 0.5408 & 0.3880 & 0.3807 & 0.3903 & 0.5408 & 0.4084 \\
\hline QG6 & 0.7467 & 0.3974 & 0.4489 & 0.4829 & 0.4521 & 0.3974 & 0.357 \\
\hline QG7 & 0.9321 & 0.7687 & 0.7070 & 0.6931 & 0.7039 & 0.7687 & 0.6195 \\
\hline QG8 & 0.1697 & 0.2988 & 0.3626 & 0.3497 & 0.3604 & 0.2988 & 0.3368 \\
\hline QS18 & 0.0000 & 0.1827 & 0.0000 & 0.0000 & 0.0000 & 0.1827 & 0.3199 \\
\hline QS20 & 0.0000 & 0.3697 & 0.4575 & 0.4575 & 0.5000 & 0.3697 & 0.3199 \\
\hline QS42 & 0.0000 & 0.0520 & 0.1945 & 0.1900 & 0.1934 & 0.0520 & 0.4256 \\
\hline $\mathbf{t}_{4-25}$ & 1.0000 & 0.9950 & 0.9570 & 0.9550 & 0.9550 & 0.9950 & 0.9750 \\
\hline $\mathbf{t}_{\text {11- 28 }}$ & 1.0000 & 0.9950 & 1.0144 & 1.0150 & 1.0150 & 0.9950 & 1.0147 \\
\hline vl18 & $0.9313^{*}$ & 1.0259 & 1.0080 & 1.0080 & 1.0080 & 1.0259 & 1.0405 \\
\hline vl20 & $0.9191{ }^{*}$ & 1.0315 & 1.0222 & 1.0222 & 1.0222 & 1.0315 & 1.0407 \\
\hline vl21 & $0.9252{ }^{*}$ & 1.0214 & 1.0125 & 1.0125 & 1.0125 & 1.0214 & 1.0304 \\
\hline Power losses & 0.1808 & 0.1558 & 0.1631 & 0.1631 & 0.1631 & 0.1558 & 0.1628 \\
\hline \% Reduction in & & 13.8335 & 9.7775 & 9.7631 & 9.8081 & 13.8335 & 9.9393 \\
\hline power losses & & 17.8066 & 17.8708 & 17.871 & 17.8706 & 17.8016 & 18.1883 \\
\hline Total QGReserve & 16.9758 & & & & & &
\end{tabular}


A. El-Ela, R. El Sehiemy and A. Shaheen "Maximal Preventive Reactive Power Dispatch Using.."

Table 5, The maximization of reactive reserve of cases 4 and 5 for West Delta system

\begin{tabular}{|c|c|c|c|c|}
\hline & Initial case & case 1 & case 4 & case 5 \\
\hline QG1 & 0.6334 & 0.2988 & 0.2673 & 0.2766 \\
\hline QG2 & -0.3790 & 0.1182 & 0.1884 & 0.1717 \\
\hline QG3 & 0.8700 & 0.1692 & 0.8120 & 0.8134 \\
\hline QG4 & 0.9766 & 0.8565 & 0.7708 & 0.7802 \\
\hline QG5 & 0.3247 & 0.5408 & 0.4378 & 0.4067 \\
\hline QG6 & 0.7467 & 0.3974 & 0.4956 & 0.5100 \\
\hline QG8 & 0.9321 & 0.7687 & 0.7456 & 0.7672 \\
\hline QS18 & 0.1697 & 0.2988 & 0.4410 & 0.4361 \\
\hline QS20 & 0.0000 & 0.1827 & 0.0000 & 0.0000 \\
\hline QS42 & 0.0000 & 0.3697 & 0.0000 & 0.0000 \\
\hline t4-25 & 0.0000 & 0.0520 & 0.0000 & 0.0000 \\
\hline vl18 & 1.0000 & 0.9950 & 0.9600 & 0.9750 \\
\hline vl20 & 1.0000 & 0.9950 & 1.0250 & 1.0250 \\
\hline vl21 & $0.9313^{*}$ & 1.0259 & 0.9724 & 0.9708 \\
\hline Power losses & $0.919 *^{*}$ & 1.0315 & 0.9613 & 0.9596 \\
\hline \%eduction in power losses & $0.9252^{*}$ & 1.0214 & 0.9674 & 0.9657 \\
\hline Total QGReserve & 0.1808 & 0.1558 & 0.1717 & 0.1735 \\
\hline *indicates to the violation of a variable & 16.9758 & 13.8335 & 5.0244 & 4.0395 \\
\hline
\end{tabular}

\section{CONCLUSION}

This paper presents an efficient procedure for the management of reactive power using the MFLP technique in order to minimize the real power losses with enhancing the voltage security at all buses to overcome any emergency may occur in power system. The MFLP technique has been successfully applied to achieve multi objective functions, which are required to obtain the optimal reactive power reserve for power systems. The optimal preventive control actions are prepared by maximizing the reactive power reserves to avoid any emergency condition and to restore the system to the normal state. With the use of the MFLP technique, the best tuning of power system variables is obtained by achieving the proposed objectives. Therefore, the proposed procedure allows the system operator to solve the emergency condition problem with minimum increase of power losses.

\section{REFERANCES}

[1] K.R.C. Mamundur, R.D. Chenoweth, Optimal control of reactive power flow for improvements in voltage profiles and for real power loss minimization, IEEE Trans. Power Appar. Systems. 100 (1981), pp. 3185-3194.

[2] Otar Gavasheli and Le Anh Tuan, 'Optimal Placement of Reactive Power Supports for Transmission Loss Minimization: The Case of Georgian Regional Power Grid', Large Engineering Systems Conference on Power Engineering Montreal, Quebec, Canada, October 10 to 12, (2007) pp. 125-130

[3] Conejo, A.J., Galiana, F.D., and Kockar, I.: 'Z-bus loss allocation', IEEE Transactions on Power Systems, Vol. 16, No. 1 (2001).
[4] D.I. Sun, B. Ashley, B. Brewar, A. Hughes, W.F. Tinny, Optimal power flow by Newton approach, IEEE Trans. Power Appar. systems. 103 (1984), pp. 2864-2880.

[5] E. Lobato, L. Rouco, M. I. Navarrete, R. Casanova and G. Lopez, "An LP-based optimal power flow for transmission losses and generator reactive margins minimization”, in Proc. of IEEE porto power tech conference, Portugal, Sept. (2001).

[6] F.C. Lu, Y.Y. Hsu, Reactive power/voltage control in a distribution substation using dynamic programming, IEE Proc. Generation Transmission Distribution 142 (1995), pp. 639-645.

[7] D. Pudjianto, S. Ahmed and G. Strbac, "Allocation of VAR support using LP and NLP based optimal power flows”, IEE Proc. Generation Transmission Distribution Vol. 149, No. 4, July (2002) pp. 377-383.

[8] N. Grudinin, "Reactive power optimization using successive quadratic programming method”, IEEE Trans. Power Systems., Vol. 13, No. 4, November. (1998), pp. 1219-1225.

[9] X. Lin, A. K. David and C. W. Yu, "Reactive power optimization with voltage stability consideration in power market systems”, IEE Proc. Generation Transmission Distribution., Vol. 150, No. 3, May (2003), pp. 305-310.

[10] S. Granville, Optimal reactive power dispatch through interior point methods, IEEE Trans. Power Systems. 9 (1994) pp. 136-146.

[11] G. A. Bakare, G. K. Venayagamoorthy, and U. O. Aliyu, "Reactive power and voltage control of the Nigerian grid system using microgenetic algorithm," in Proc. IEEE Power Eng. Soc. General Meeting, San Francisco, CA, vol. 2, (2005), pp. 1916-1922. 
A. El-Ela, R. El Sehiemy and A. Shaheen "Maximal Preventive Reactive Power Dispatch Using.."

[12] H. Yoshida et al., “A particle swarm optimization for reactive power and voltage control considering voltage security assessment," IEEE Trans. Power Systems., Vol. 15, No. 4, November. 2001, pp. 12321239.

[13] G. Cai, Z. Ren, and T. Yu, “Optimal reactive power dispatch based on modified particle swarm optimization considering voltage stability," in Proc. IEEE Power Eng. Soc. General Meeting, (2007), pp. 1-5.

[14] M. Varadarajan and K. S. Swarup, "Network loss minimization with voltage security using differential evolution," Electeric Power System Research., Vol. 78, (2008), pp. 815823.

[15] M. Varadarajan and K. S. Swarup, "Differential evolutionary algorithm for optimal reactive power dispatch,” International Journal of Electrical Power \& Energy Systems., Vol 30, October (2008), pp.435-441.

[16] US-Canada Power System Outage Task Force, Final Report on the August 14, 2003 Blackout in the United States and Canada: Causes and Recommendations, Issued April (2004).

[17] Wu H, Yu CW, Xu N, Lin XJ. “An OPF based approach for assessing the minimal reactive power support for generators in deregulated power systems”, International Journal of Electrical Power \& Energy Systems 30(1), (2008), pp. 23-30.

[18] He R, Taylor GA, Song YH. "Multi-objective optimal reactive power flow including voltage security and demand profile classification”, International Journal of Electrical Power \& Energy Systems 30(5), (2008), pp. 327-36.

[19] L.D. Arya, L.S. Titare and D.P. Kothari "Improved particle swarm optimization applied to reactive power reserve maximization”, Electrical Power and Energy Systems 32 (2010) pp. 368-374
[20] Takashi Hiyama,and Kevin Tomsovic "Current status of fuzzy system applications in power systems" Systems, Man, and Cybernetics, 1999. IEEE, SMC '99 Conference Proceedings 1999 IEEE International Conference on Publication Date: Vol.6, (1999), pp. 527 - 532, Location: Tokyo

[21] K. Tomsovic, M.Y. Chow, "Tutorial on fuzzy logic applications in power systems” Prepared for the IEEE-PES Winter Meeting in Singapore January, 2000

[22] J.A.Momoh SM, X.W.MA, and K Tomsovic "Overview and literature survey of fuzzy set theory in power system” IEEE, Vol 10, No 3, August1995.

[23] A. A. Abou EL-Ela, M. Bishr, S. Allam, and R. El-Sehiemy,, "Optimal power dispatch using different fuzzy constraints power systems,” International Energy Journal, Volume 8, Issue 3, September 2007.

[24] A. A. Abou EL-Ela, M. Bishr, S. Allam, and R. El-Sehiemy, "Optimal Preventive Control Actions Using Multi- Objective Fuzzy Linear Programming Technique”, Electric Power System Research Journal, Vol. 74, Issue 1, April (2005), pp. 147-155

[25] A. A. Abou El-Ela and M. A. Abido, "Optimal operation strategy for reactive power control," Modeling, Simulation \& Control, Part A, Vol. 41, No. 3, (1992), pp. 19-40.

[26] A.A. Abou, R. El-Sehiemy,and A. M. Shaheen, "Multi-Objective Fuzzy Based Procedure for Optimal Reactive Power Dispatch Problem", Proceedings of the 14th International Middle East Power Systems Conference (MEPCON'10), Cairo University, Egypt, December 19-21, (2010), Paper ID 312. pp. 941-946

[27] A.A. Abou El-Ela S.M. Allam, M.M. Shatla, "Maximal optimal benefits of distributed generation using genetic algorithms," Electric Power Systems Research 80 (2010), pp.869877. 